University of New Mexico

UNM Digital Repository

Biology Faculty \& Staff Publications

Academic Department Resources

4-28-1977

\title{
When is sex environmentally determined?
}

Eric Charnov

James Bull

Follow this and additional works at: https://digitalrepository.unm.edu/biol_fsp

Part of the Biology Commons

\section{Recommended Citation}

Charnov, E.L. and J.J. Bull. 1977. When is sex environmentally determined? Nature 266:828-830

This Article is brought to you for free and open access by the Academic Department Resources at UNM Digital Repository. It has been accepted for inclusion in Biology Faculty \& Staff Publications by an authorized administrator of UNM Digital Repository. For more information, please contact disc@unm.edu. 


\section{When is sex environmentally determined?}

THERE are several sex determining mechanisms which produce two sexes in a population (dioecy or gonochorism) ${ }^{1-5}$. In many of these, the offspring's sex is determined at or before conception, as in male or female heterogamety. In several organisms, however, the offspring's sex is determined later than conception, by some environmental influence upon the offspring. We consider here why these environmental mechanisms have been maintained; that is, why have they not been replaced with an alternative system that determines sex at conception? We propose that labile sex determination (not fixed at conception) is favoured by natural selection when an individual's fitness (as a male or female) is strongly influenced by environmental conditions and where the individual has little control over which environment it will experience. Our argument also applies to sex expression in hermaphrodites ${ }^{6,7}$.

The basis of a theory of labile sex determination lies with two principles, first noted by Fisher ${ }^{8}$, who applied them to sex ratio evolution:(1) both sexes contribute autosomal genes equally to the next generation, that is, everyone has a mother and a father, and (2) the fitness of an individual is measured relative to others of the same sex. Relative fitness is the ratio of an individual's actual fitness (survival $\times$ fertility) to the average fitness in that sex and must account for the relative abundances of both sexes. Selection thus favours the ability of a parent or offspring to manipulate the sex ratio to result in offspring with the highest fitness in each sex ${ }^{9}$.

To illustrate, if an individual finds itself in an environment where it can become a below average female or an above average male, selection will favour its becoming male because it can pass on more of its genes than if it were female. Selection may therefore favour 'environmental sex determination' (ESD) because of the control it allows an individual. When sex is determined at conception, the individual no longer has this control but can begin 'developing into' its sex immediately. Early development of sex allows an individual to become a better male or female and is probably the major advantage of genotypic sex determination.

Selection should most strongly favour ESD when (1) the offspring enters an environment, away from the parent, which has a large effect on its lifetime fitness; this environment is patchy, some patches conferring more of an advantage to females than to males and vice versa; and (2) the offspring and parent have little control (or predictive ability) over which patch type the offspring enters. These conditions make it unfavourable to determine sex at conception because of the possibility that a male will enter a patch that is much more favourable for a female, or the reverse.

There are several ways in which an environment may be 'patchy' relative to the selective value of being a male or a female. (1) There is local competition for mates. If an area has a high concentration of females and a low concentration of males, then an individual enjoys the greatest success when it is a male. (2) Resources may have differential value to males or females, and they may be patchy in distribution. If an offspring must garnish most of its resources in a restricted environment, and if there is a sex difference in the advantage of the resource, then the offspring should become the sex which benefits the most under the circumstances. Resources which may have differential value to sex function include sunlight (in plants) and other nutrients for growth (a large size is often more advantageous to one sex than the other). (3) Predation (or other mortality sources) may be patchy and could be sex specific.

The inability of the parent or offspring to choose a patch type also has a major role in favouring ESD. If an offspring can choose its patch, sex can be determined at conception and the offspring enters the patch that will give its sex the highest fitness. Inability to choose patch type will often be correlated with immobility; however, parental mobility does not preclude ESD. If parents deposit offspring in (or offspring enter) environments from which they cannot escape during some crucial stage of development, selection may favour an environmental mechanism when the parent or offspring is unable to evaluate the patch type prior to entry. In contrast, if the parent can evaluate the patch (but the offspring cannot leave it), selection may favour parental ability to match the sex of the offspring to the appropriate patch. Such mechanisms occur among parasitic Hymenoptera ${ }^{10,11}$.

Environmental sex determination is known in several plants and animals, and these seem to fulfil the expected characteristics.

Many species of nematodes which parasitise insects (family Mermithidae) and some which parasitise plants (genera Meloidogyne and Heterodera) are believed to have $\mathrm{ESD}^{2,12-14}$. The life histories are basically alike: young (eggs) are either deposited on a host or they locate a host and enter. The larvae attain almost adult size while in the host. Adults (at least males) leave and mate outside the host ${ }^{12,15}$

The sex of the nematode is determined after entering the host, and sex ratio varies with parasite density inside the host. High density results in an abundance of males, whereas low density results in mostly females, ${ }^{2-14}$. Large size is apparently more important to female than to male fitness (females are universally the larger sex in nematodes). Thus a juvenile in a crowded host will not be able to attain a large size; it can become an average male or a below average female: selection should favour it becoming the male. In uncrowded hosts, an individual gains more as a female.

Among marine invertebrates, ESD is known in Bonellia (an echiurid), and several parasitic isopods (for example, Stegophryxus and Ione $)^{2,3,16}$. These organisms usually have dwarf males which live on the female. Larvae are planktonic and adults are immobile (Bonellia) or are restricted to the host. Larvae that settle alone become females, those that attach to females become males. In these, the resource of strongest sex-dependent value is the female, because of the ability of the male to remain small, live upon her and fertilise her eggs. The example of parasitic males partially violates the condition that the organism be unable to choose patch type. A larva that encounters a female can probably choose to avoid settling on her. Despite this, the absence of choice still largely applies because all larvae presumably do not encounter females (or do not have the choice to). Therefore, a larva that differentiated into a male too early would not be guaranteed to encounter a female.

Sex may also be environmentally determined in monstrillid crustaceans ${ }^{12}$. These parasitic copepods have life cycles similar to the nematodes discussed above in that the adults are free and mobile, and most of the larval growth takes place inside the host. As in nematodes, crowding in the host results in a preponderance of males.

Among higher plants, there are numerous examples of dioecious species where some individuals change sex between seasons of reproductive activity ${ }^{4,5,17}$; this provides evidence for the widespread occurrence of ESD in a group where it was previously given very little attention ${ }^{18,19}$. Also, there are many cases where male and female plants occupy different habitats, suggesting ESD or perhaps differential mortality by sex ${ }^{17}$.

Several well-documented examples of plants with ESD are orchids of the genera Cycnoches and Catasetum ${ }^{20.21}$. Sunlight seems to be the resource which is differentially beneficial. Plants grown in bright sunlight become female, those grown in shade become male. Also, larger plants tend to be female. It is not clear why sunlight is more important to femaleness than to maleness (why should it be more important to seed production than pollen production?), but the pattern is well documented.

The arguments have been thus far directed towards maleness against femaleness in dioecious species. Natural selection should also favour the ability of a hermaphrodite living in a patchy 
environment to alter its allocation of resources between male and female function?

A sequential hermaphrodite should exercise control over the time at which it changes sex in accord with the above idea. As fitness of the second sex is often size dependent, it should often change sex according to size rather than age. For example, if an individual is reduced in size just before the expected size of sex change, it should remain the first sex until recuperated from the perturbation. Examples of this are well documented: in a polychate (Ophryotrocha puerilis) ${ }^{2}$ and a plant (Arisaema triphyllum $^{4,5,22,23}$. Other examples of labile sex change, related to male against female fitness, are also known in fish (the labrid, Labroides dimidiatos) ${ }^{24}$ and some marine gastropods (for example, Crepidula $)^{2,25}$

In a simultaneous hermaphrodite, selection should favour the ability to alter the ratio of sperm (pollen) to ova (seeds) produced in response to environmental conditions ${ }^{7}$ (as simultaneous hermaphroditism is commonly associated with immobility in the adult stage $)^{6}$. Examples seem to be scanty, but the reallocation in monoecious plants due to factors such as nutrition or sunlight is well documented ${ }^{4,5,26,27}$ (C. Smith, personal communication), particularly in the Russian literature ${ }^{28}$.

Interestingly, this suggests that one selective advantage of monoecy in plants is that it allows the use of hormonal systems to control male against female allocation. This alteration is as simple as changing the ratio of male to female flowers. Supporting this idea is the observation that populations consisting of males, females and monoecious individuals are among the most common of all types of mixed populations in plants ${ }^{29}$. We interpret the males or females as hermaphrodites who have reallocated resources to one or the other sex. Such lability would seem to be less possible in plants with hermaphroditic flowers.

As this paper was being written we became aware that similar ideas were being developed in four other labs: K. E. Hoagland with protandrous molluscs; C. Smith for monoecious trees; L. Gilbert and $\mathbf{M}$. Condon for protandrous vines; and C. Freeman, $\mathrm{K}$. Harper and L. Klikoff for dioecious plants. We acknowledge their independent thought. We thank G. C. Williams, R. Shine, J. Cranford, J. Werren, N. Negus, P. Berger, G. H. Orians, J. Maynard Smith and Thomas Gibson for cooperation. This work was supported by a grant from the PHS.

ERIC L. CHARNOV

Department of Biology, JAMES BULL

University of Utah,

Salt Lake City, Utah 84112

Received 10 December 1976; accepted 22 February 1977.

1 White, M. J. D. Animal Cytology and Evolution, third edn (Cambridge University, Cambridge, 1973).

2 Bacci, G. Sex Determination (Pergamon, Oxford, 1965).

3 Reinboth, R., ed. Intersexuality in the Animal Kingdom (Springer, Berlin, 1975).

Heslop-Harrison, J. Biol. Rev. 32, 38-90 (1957)

Heslop-Harrison, J. in Plant Physiology (ed. Steward, F. C.), 4C, 133-290 (Academic, New

York, 1972). The Economy of Nature and the Evolution of Sex (University of California, Berkeley, 1974)

Charnoy, E. L. Maynard Smith, J. \& Bull, J. Nature 263, 125-126(1976).

- Fisher, R. A. The Genetical Theory of Natural Selection (Oxford University, Oxford, 1929).

Trivers, R. L. \& Willard, D. E. Science 179, $90-92$ (1973)

Flanders, S. E. Am. Nat. $99,489-494(1965)$.

2 Christie, J. R. J. exp. Zool. 53, 59-65(1929).

3 Christie, J. R. J. exp. Zool. 53, 59-65(1929).

14 Anya, A. O. Adv. Parasit. 14, 268-351 (1976).

is Wallace, H. R. The Biology of Plant Parasitic Nematodes, 1 (Edward Arnold, London, 1963). Gould-Somero, M. in Reproduction of Marine Invertebrates (eds Giese, A. C. \& Pearse, J. S.) (Academic, New York, 1975).

17 Freeman, C., Klikoff, L. \& Harper, K. Science 193, 579 (1976)

13 Westergaard, M. Adv. Genet. 9, 217-281 (1958).

19 Lewis, D. Biol. Rev. 17, 46-67 (1942)

Dodson, C. H. Ann. Missouri Bot. Gard. 49, 35-56(1962)

21 Gregg, K. B. Selbyana 1, 101-113(1975)

22 Schaffer, J. H. Am. J. Bot. 9, $72-78(1922)$

Camp, W. H. Ohio J. Sci. 32, 147-151 (1932)

Robertson, D. R. Science 177, $1007-1009$ (1972)

2s Coe, W. R. J. exp. Zool. 108, 155-170 (1948)

26 Kooistra, E. Euphytica 16, 1-17 (1967)

27 Williams, C. N. \& Thomas, R. L. Ann. Bot. 34, 957-963 (1970)

20 Pamplonsky, C. \& Yamplonsky, H. Bibl. Genet. 3, 1-62 (1922). 